\title{
Series Arc Fault Breaker in Low Voltage Using Microcontroller Based on Fast Fourier Transform
}

\author{
Dimas Okky Anggriawan, Audya Elisa Rheinanda, Muhammad Khanif \\ Khafidli, Eka Prasetyono, Novie Ayub Windarko \\ Politeknik Elektronika Negeri Surabaya \\ E-mail: audyaelisa27@gmail.com,khanifkhafidli@gmail.com, eka@pens.ac.id, \\ ayub@pens.ac.id \\ Correspondence Author: dimas@pens.ac.id
}

Received August 15, 2021; Revised September 19, 2021; Accepted October 24, 2021

\begin{abstract}
Series Arc Fault is one of the disturbances of arcing jump is caused by gas ionization between two ends of damaged conductors or broken wire forming a gap in the insulator. Series arc fault is the primary driver of electrical fire. However, lack of knowledge of the disturbance of series arc fault causes the problem of electrical fire not be mitigated. Magnitude current is not capable to detect of series arc fault. Therefore, this paper proposes fast fourier transform (FFT) to detect series AC arc fault in low voltage using microcontroller ARM STM32F7NGH in real time. A cheap and high speed of microcontroller ARM STM32F7NGH can be used for FFT computation to transform signal in time domain to frequency domain. Moreover, in this paper, protection of series AC arc fault is proposed in the real time mode. In this experimental process, some various experiments are tested to evaluate the reliability of FFT and protection with various load starts from $1 \mathrm{~A}, 2 \mathrm{~A}, 3 \mathrm{~A}, 4 \mathrm{~A}$ in resistive load. The result of this experiment shows that series AC arc fault protection with STM32F7 microcontroller and FFT algorithm can be utilized to ensure series AC arc fault properly.
\end{abstract}

Keywords: fast fourier transform, Microcontroller, Protection, series AC Arc fault, Real-time

\section{INTRODUCTION}

One of the electrical risks arises from the utilization of electricity could be a series arc fault or parallel arc fault. Series Arc Fault is one of the disturbances of arcing jump is caused by gas ionization between two ends of damaged conductors or broken wire forming a gap in the insulator. There are several factors that generally cause series arc fault such as cables are old or damaged, cables are peeled off, cables get contact with metal objects, electrical cables are too hot or depressed, and non-standard connections [12], [14]. A series arc fault contains a high temperature may cause fire. However, the series arc fault does not current increase significantly [1]-[8]. 
Arcing fault current interrupter (AFCI) is one among the protections systems for low voltage power lines to stop fire accidents from arc faults. Protection system must be considered especially the reliability of the system when isolate the series arc fault. However, the probability of a commercial AFC to protect of series arc fault is around 50\% within the test report [17].

The disturbance of series AC arc faults has different characteristics with other disturbances. Parallel AC arc fault has characteristic when fault occurs, current increase significantly. Moreover, overload disturbances also have current increase significantly without change of frequency. Both problems only require the detection of the magnitude of the amplitude in time domain. However, the series AC arc fault contains a fault current with the frequency of disturbance varies from $50 \mathrm{~Hz}$ to $1 \mathrm{G} \mathrm{Hz}$ and the temperature is quite high. Series AC arc fault difficult to detect. Therefore, a simple, accurate, and affordable is required to detection of series AC arc fault.

This paper proposes a series AC arc fault detection and protection system in low voltage level using microcontroller in the real time mode. ARM STM32F7NGH microcontroller at a low price and a high-speed can be used for fast Fourier transform computing of waveform from the time domain to the frequency domain. Moreover, the protection of series AC arc fault is introduced. Evaluation experiment of a series AC arc fault detection and protection are proposed in several test conditions. The result shows compatibility for the aim of series AC arc fault detection and protection systems.

\section{RELATED WORKS}

Many algorithms are proposed to series AC arc fault detection [1]-[8]. Detection of series AC arc fault using conventional methods with physical phenomena. Conventional methods difficult to detect of series AC arc fault because does not know when occurs of series AC arc fault. Detection of series $\mathrm{AC}$ arc using the change of voltage and current is introduced in the time domain [7]-[8]. However, the change of voltage and current may be caused by harmonic, voltage flicker, overvoltage and the other faults, which influences error identification. Series AC arc fault occurs when magnitude appears in frequencies other than $50 \mathrm{~Hz}$. To obtain detect accurately of AC series arc fault using FFT, which it can transform signal in time domain to frequency domain [9]. Series DC arc fault in frequency domain becomes easy to be analyzed. In many papers, FFT is operated in offline mode. Therefore, the contribution in this research is detection AC arc fault using FFT in real-time mode.

To mitigate series AC arc fault causes fire hazard so that fast and accurate protection is required. FFT has characteristics easy implementation, accurate result and fast computation, which suitable as method to protect series AC arc fault. In this paper, protection of series AC arc fault is implemented by hardware system, which consists of microcontroller, series $\mathrm{AC}$ arc fault generator, current sensor and relay. Arm STM32F7 is chosen as microcontroller to run the proposed method. Arm STM32F7 is equipped by 
12-bit A/D converter and frequency of $167 \mathrm{Mhz}$ so that it has good performance for analyze of series AC arc fault. Moreover, Arm STM32F7 supports series AC arc Fault protection to be operated in real time mode.

Table 1. State of the art in the paper

\begin{tabular}{|l|l|l|l|l|}
\hline \multicolumn{1}{|c|}{ Author } & \multicolumn{1}{|c|}{ Method } & \multicolumn{1}{c|}{ Testing } & \multicolumn{1}{c|}{ Mode } & Protection \\
\hline Artale, G et al & $\begin{array}{l}\text { Physical } \\
\text { phenomena }\end{array}$ & Experimental & Off line & None \\
\hline Zang, W et al & $\begin{array}{l}\text { the change of } \\
\text { voltage and } \\
\text { current }\end{array}$ & Experimental & Off line & None \\
\hline $\begin{array}{l}\text { Stroble, C et } \\
\text { al }\end{array}$ & $\begin{array}{l}\text { the change of } \\
\text { voltage and } \\
\text { current }\end{array}$ & Simulation & Off line & None \\
\hline Ji, S.C et al & FFT & Simulation & Off line & None \\
\hline $\begin{array}{l}\text { The } \\
\text { proposed } \\
\text { method }\end{array}$ & FFT & Experimental & Real-Time & Yes \\
\hline
\end{tabular}

\section{ORIGINALITY}

Basically, arc faults can be detected by changing the form of current waveforms and rating current waveforms in the system [13]. However, there are also researchers who conduct the detection through voltage amplitude and waveform changes from the system voltage, by compare the estimates of an arc voltage amplitude with the threshold given [14].

A simple, accurate, and affordable of series AC arc fault protection is required. This paper proposes series $\mathrm{AC}$ arc fault detection and protection system using FFT with microcontroller in mode real time. The high speed of ARM STM32F7NGH microcontroller can be used for FFT to transform waveform the time domain to the frequency domain. Moreover, the protection of series AC arc fault is introduced. To check the performance of proposed algorithm, Experimental is conducted by vary of the current level. Evaluation experiment of a series AC arc fault detection and protection are proposed in several test conditions. The result shows compatibility for the aim of series AC arc fault detection and protection systems.

\section{SYSTEM DESIGN}

\subsection{EXPERIMENTAL OF SERIES AC ARC FAULT}

\subsubsection{Summary of series AC arc fault characteristic.}

The AC arc fault is classified into three categories, namely, series AC arc fault, parallel AC arc fault and line to ground arc fault. Parallel AC arc fault is typically caused by a short circuit between a phase line and a neutral line. A significant increase in current level is an indication of parallel AC arc fault. 
Whereas, series AC arc fault usually occur in series on a neutral line or line where the current level same compared by the normal current. Parallel AC arc fault normally caused by direct contact between the phase line and the line ground.

The existing protection device is mostly focused on protecting devices from short circuit and from ground faults, as yet there is not available protection device that protect from series AC arc faults.

From several experiments have been carried out [6], [8] the current characteristics during series AC arc fault can be identified, including:

1. The current waveform of series AC arc fault has design as shoulder in zero point

2. The current amplitude level of series AC arc fault decrease by $80 \%$ from the normal current amplitude

3. Non-stationary waveforms maybe change in each cycle.

4. The frequency of series AC arc fault occurs starting from frequencies of more than $50 \mathrm{~Hz}$ to less than $1 \mathrm{GHz}$.

The detection of series AC arc fault more difficult compared to short circuit fault because the current waveform of series AC arc fault waveform has design as normal condition waveform. Therefore, the research is focused on the analysis of the series AC arc fault characteristics in resistive loads using FFT and the protection system is proposed to isolate series AC fault.

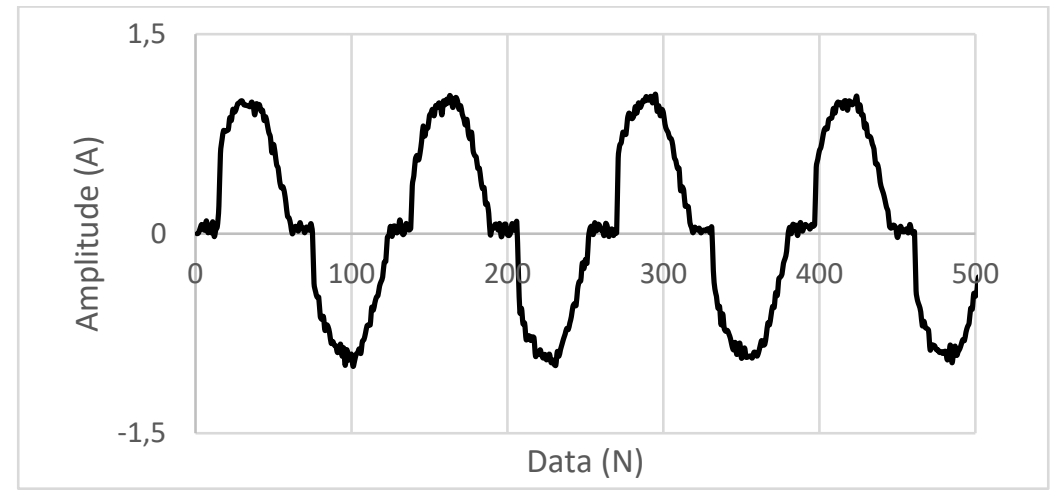

Figure. 1. Series AC arc fault waveform

\subsubsection{Hardware System}

Figure 2 is an arc generator scheme and figure 3 is a block diagram of a series of arc fault breakers. Arc generator is one of the mechanical simulator models to generate the series AC arc fault. Arc generator can be installed series with load. Arc generator is designed similar to real condition, which real condition use a system with voltage of $220 \mathrm{~V}$ and frequency of $50 \mathrm{~Hz}$. Figure 3 show that the process of transform analog signal data into digital signals from current and voltage through STM32F7 ADC microcontroller. Moreover, the hardware system equipped by zero crossing detection as interrupt process to start and end computation. 
Furthermore, STM32F7 microcontroller capable to highspeed sampling process until $100 \mathrm{kHz}$. FFT transforms digital signal data from the time domain to the frequency domain. The result of FFT is stored in the SC Card on ARM STM32F7NGH microcontroller. The algorithm of protection identifies of series AC arc fault based digital signal in frequency domain. The algorithm of protection action $\mathrm{CB}$ to trip if recognize event of series $\mathrm{AC}$ arc fault.

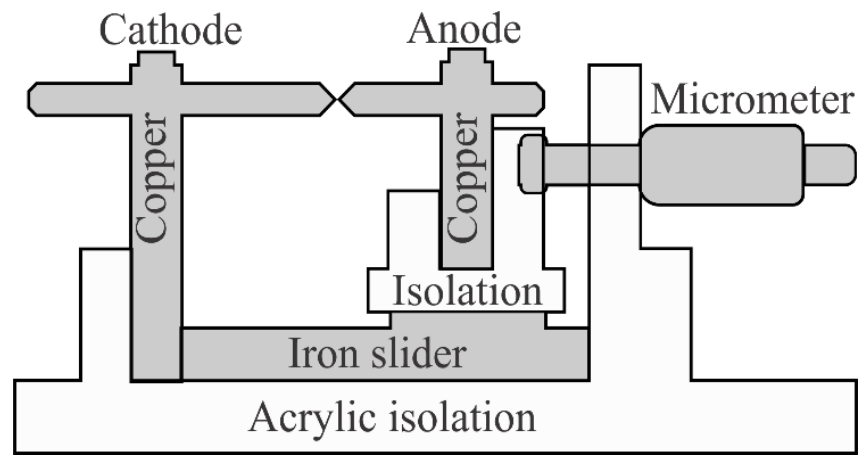

Figure. 2. Arc generator schemes

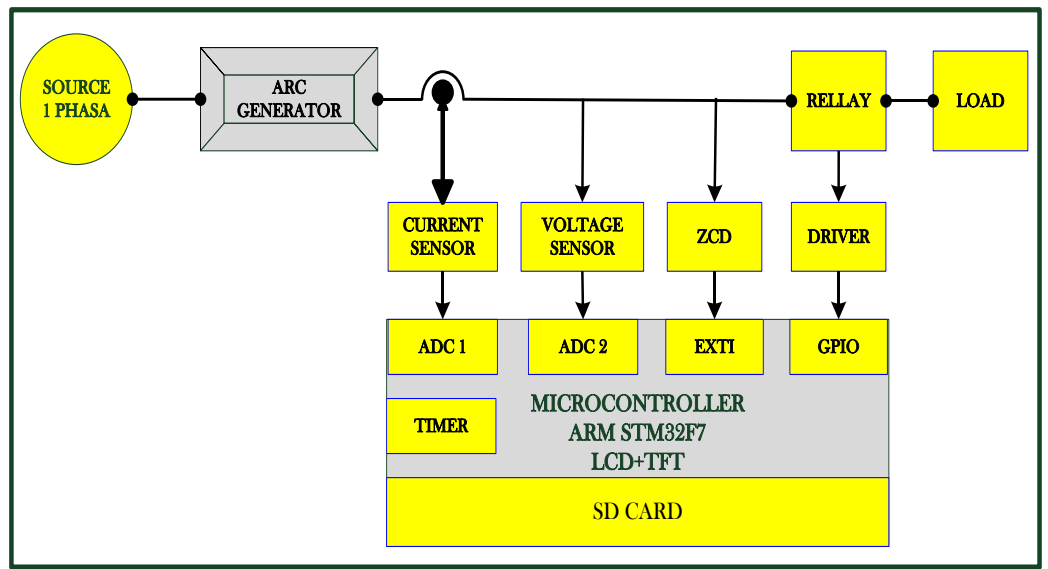

Figure. 3. Series AC Arc Fault Block Diagrams

\subsubsection{Test Conditions}

To evaluate the proposed algorithm, experimental tests are implemented by various models such as

1. Experimental test of computational time FFT in STM32F microcontrollers with variations of waveform length

2. Experimental test of system characteristic without series AC arc fault in current level of $1 \mathrm{~A}$ to $4 \mathrm{~A}$ and voltage of $220 \mathrm{~V}$.

3. Experimental test of system characteristic with series AC arc fault in current level of $1 \mathrm{~A}$ to $4 \mathrm{~A}$ and voltage of $220 \mathrm{~V}$.

4. Experimental test of protection system of series AC arc fault in current level of $1 \mathrm{~A}$ to $4 \mathrm{~A}$ and voltage of $220 \mathrm{~V}$. 


\subsection{THE PROPOSED ALGORITHM}

The proposed algorithm to detection of series AC arc fault is FFT. FFT is used because capable to detect of series AC arc fault accurately. Moreover, FFT has fast computation and easy implementation. FFT transform series AC arc fault waveform in time domain to frequency domain.

There are several stages in process of FFT. First stage, zero crossing detector in analog signal as initial process of ADC. Furthermore, The ADC process is carried out by carrying out the process of continuously sampling analog data periodically with a certain time. The ADC process is carried out by process of continuously sampling analog data periodically with a certain time. the interrupt from ZCD as the initial process of ADC is started. ADC process has frequency sampling of $6400 \mathrm{~Hz}$. Third stage, FFT computation to detection of series AC arc fault. Figure. 4. Show flowchart of the proposed algorithm to detection of series AC arc fault.

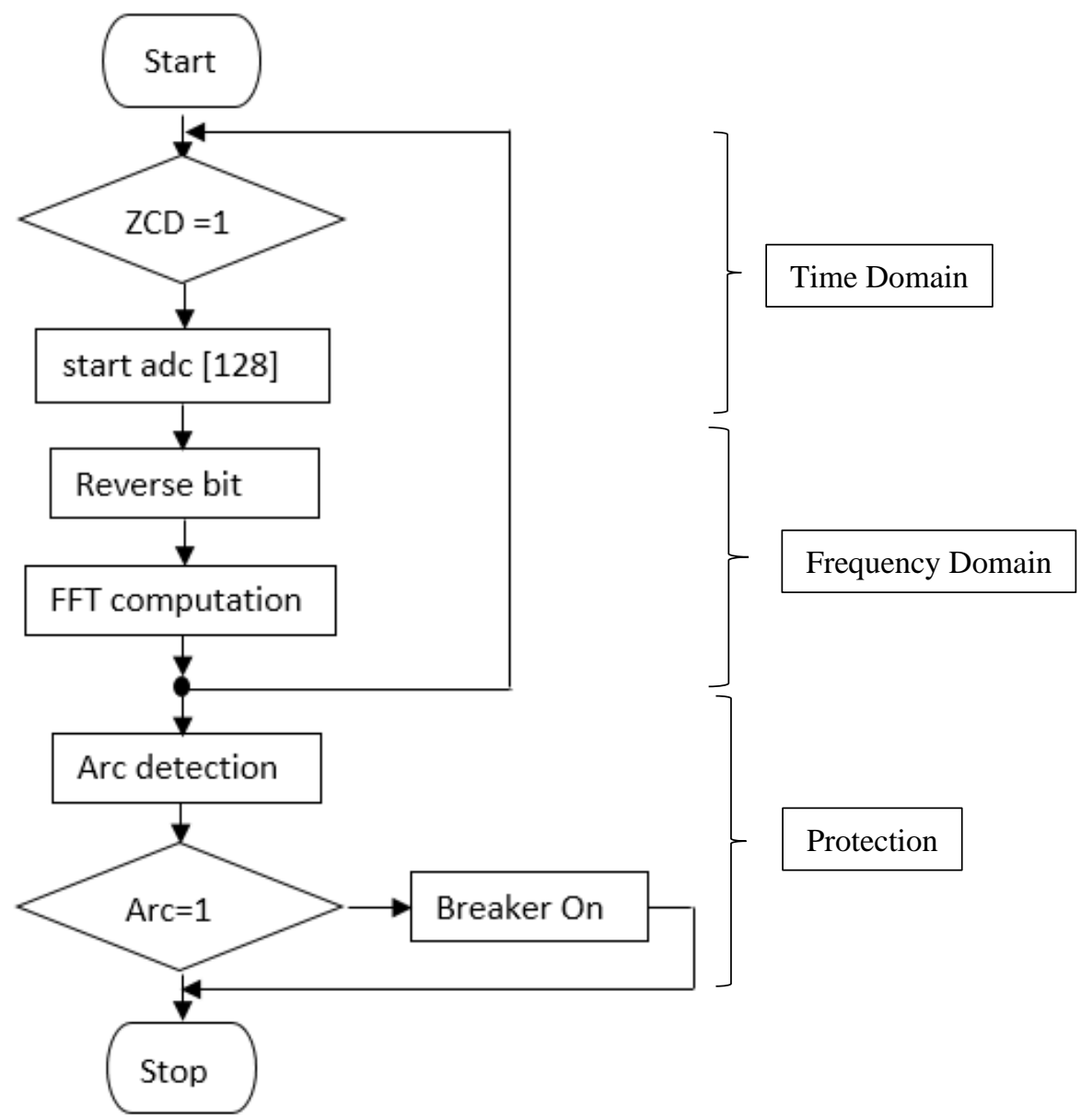

Figure. 4. The Proposed Algorithm to detection and protection of series AC arc Fault 
FFT computation using the Radix-2 DIT method, which is done with 3 stages. The first stage is to divide the incoming data into 2 arrays, namely, data with an even index and data with an odd index. Then, each pair of data is crossmultiplied, which the process is named of butterfly operation. Second stage, the results of each cross multiplication in the first stage are cross-multiplied. The third stage, multiplication of each result value from second stage with data of odd indexes and even indexed data. The Figure. 5 show FFT program in STM32F7 microcontroller.

\begin{tabular}{|c|c|}
\hline $\begin{array}{l}n 1=0 ; /^{*} F F T^{*} / \\
n 2=1 ; \\
\text { for }(i=0 ; i<m ; i++) \\
\{ \\
n 1=n 2 ; \\
n 2=n 2+n 2 ; \\
e=-6.283185307179586 / n 2 ; \\
a=0.0 ; \\
\text { for }(j=0 ; j<n 1 ; j++) \\
\{ \\
c=\cos (a) ; \\
s=\sin (a) ; \\
a=a+e ; \\
\}\end{array}$ & $\begin{array}{l}\text { for }(k=j ; k<n ; k=k+n 2) \\
\{ \\
t 1=c^{*} x[k+n 1]-s^{*} y[k+n 1] ; \\
t 2=s^{*} x[k+n 1]+c^{*} y[k+n 1] ; \\
x[k+n 1]=x[k]-t 1 ; \\
y[k+n 1]=y[k]-t 2 ; \\
x[k]=x[k]+t 1 ; \\
y[k]=y[k]+t 2 ; \\
\}\}\} \\
\text { for }\left(k=0 ; k<2^{*} N ; k++, x++\right) \\
\{ \\
\text { mag[x]=sqrt }(\operatorname{pow}(x[k], 2)+\operatorname{pow}(y[k], 2) \\
\} \\
\} \\
\}\end{array}$ \\
\hline
\end{tabular}

Figure. 5. Program of FFT in STM32F7 microcontroller

Detection of series AC arc fault based on the current magnitude that appears on the frequency of disturbance. The current level of normal condition and series AC arc fault are determined based on the magnitude current level in frequency of disturbance. The protection system operates if the magnitude current level in frequency of disturbance exceeds the predetermined minimum limit. The minimum magnitude current limit in frequency of disturbance for series AC arc fault is 180 . The protection system operates action of breaker to trip. In the figure. 6, show program of series AC arc fault protection.

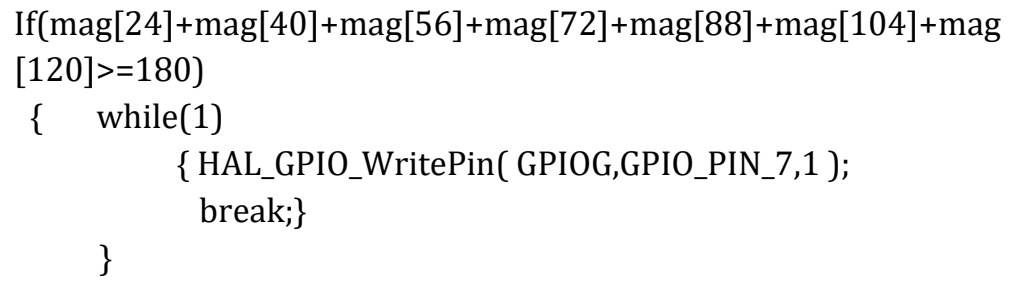

Figure. 6. Program of series AC arc fault protection 


\section{EXPERIMENTAL RESULT AND ANALYSIS}

To evaluate and check of the proposed algorithm, experimental testing is performed. There are various experimental tests to evaluate perform of the proposes algorithm such as computation time of FFT, characteristic of series AC arc fault and protection system of series AC arc fault. in the Figure. 7, show that experimental design of series $\mathrm{AC}$ arc fault detection and protection. Experimental design consists of series AC arc fault generator, hardware system, variable load, circuit breaker and voltage regulator. To evaluate of the hardware system, current level is varied of $1 \mathrm{~A}, 2 \mathrm{~A}, 3 \mathrm{~A}$ and $4 \mathrm{~A}$ with voltage of $220 \mathrm{~V}$.

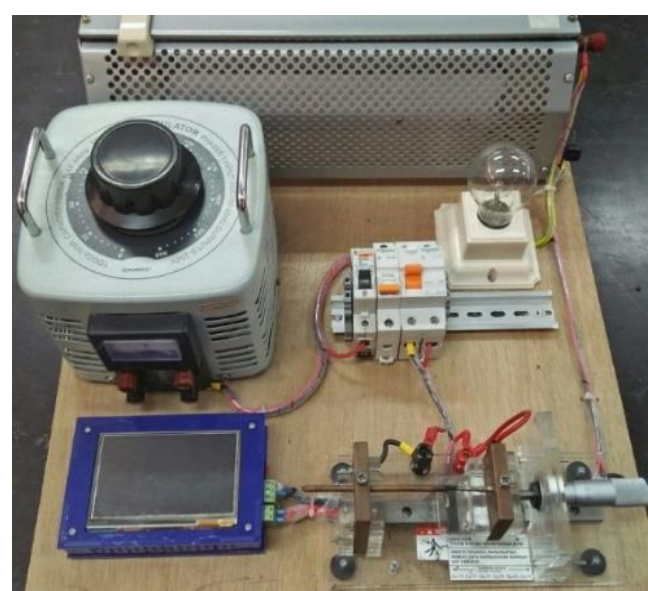

Figure. 7. Experimental Design of series $\mathrm{AC}$ arc fault detection and protection

\subsection{Time FFT Computation}

To determine the performance of STM32f7 microcontroller, Computation time of FFT is tested. In the experimental test, waveform variations are carried out by data range of $1,2,4,8,16,32$, and 64 waveforms. in the figure 8, show numbers of waveform.

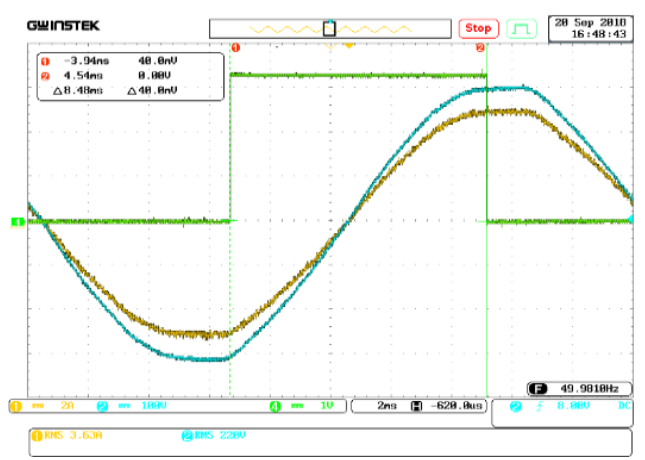

Figure. 8(a). Computation on 1 waveform

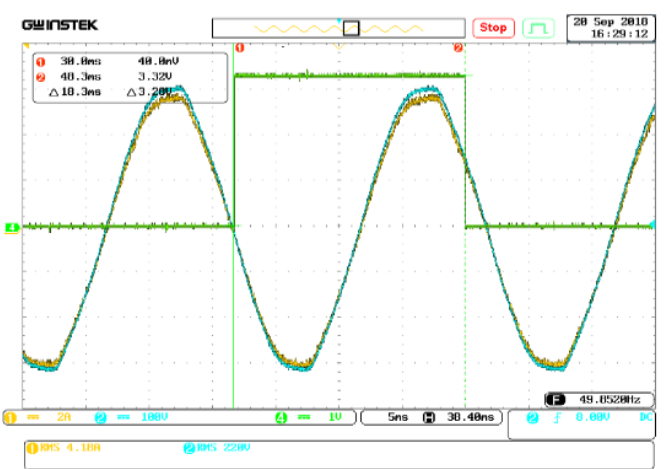

Figure. 8(b). Computation on 2 waveform 


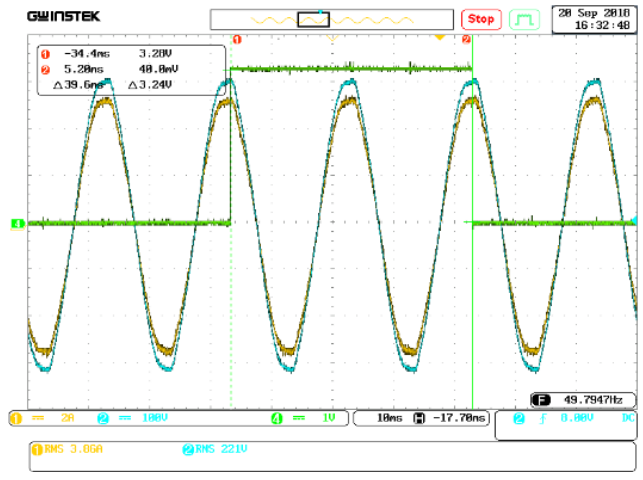

Figure. 8(c). Computation on 4 waveform

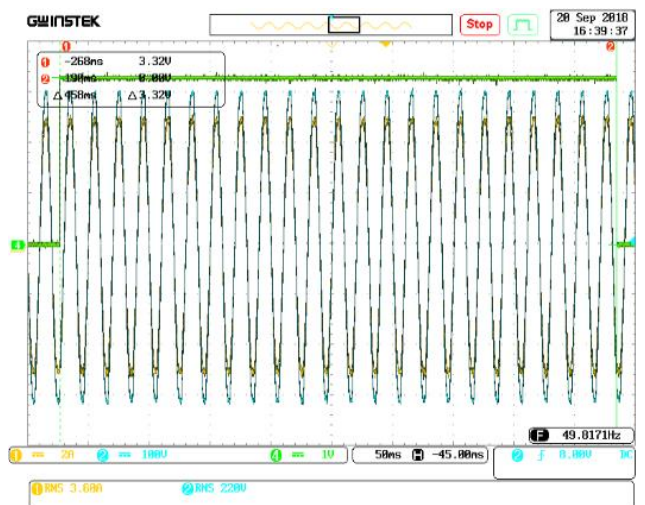

Figure. 8(e). Computation on 32 waveform Figure. 8(f). Computation on 64 waveform

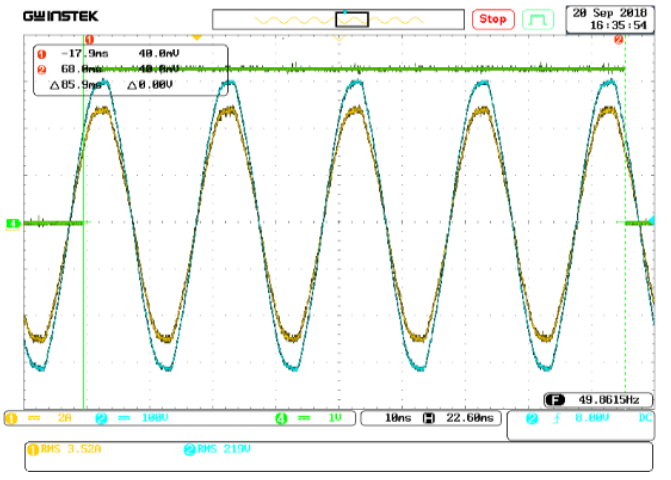

Figure. 8(d). Computation on 8 waveform

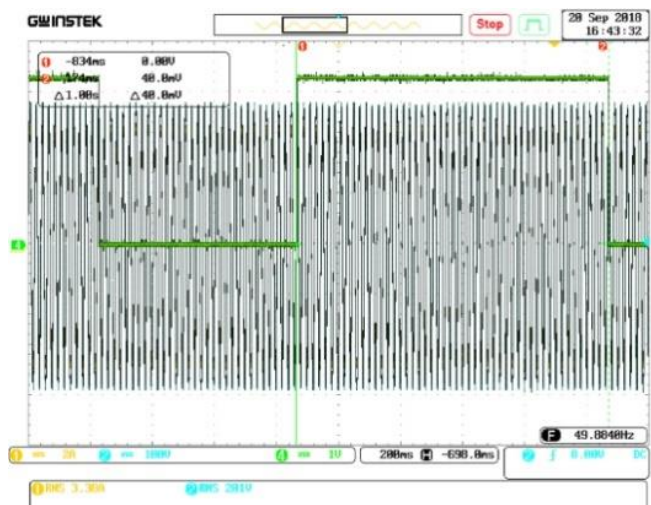

From the experimental test, Figure 8 (a) shows that the time is required to compute the FFT in 1 waveform with 128 data is 0.0084 s. Figure 8 (b) shows that the time is required to compute the FFT in 2 waveforms with 256 data is $0.0183 \mathrm{~s}$. Figure 8 (c) shows that the time is required to process the computation of FFT in 4 waveforms with 512 data is $0.0396 \mathrm{~s}$. Figure 8 (d) shows that the time is required to process the computation of FFT in 8 waveforms with 1024 data is 0.0859 s. Figure 8 (e) shows that the time is required to process the computation of FFT in 32 waveforms with 4096 data is $0.458 \mathrm{~s}$. Figure 8 ( $\mathrm{f}$ ) shows that the time is required to compute the FFT in 64 waveforms with 8192 data is $1 \mathrm{~s}$.

\subsection{Experimental Test of Series AC Arc fault Characteristic}

To evaluate characteristic of series AC arc fault, Experimental test of series $\mathrm{AC}$ arc fault and normal condition is performed on the STM32F7 microcontroller. The experimental test is performed to identify series AC arc fault, which it as reference to protection system. To identify series AC arc fault, experimental test using FFT to transform current waveform in time domain to frequency domain. Experimental tests are varied by current level of 1A, 2A, 3A, and $4 \mathrm{~A}$ are shown in figure. 9 (a) - (b). 
The experimental test result in figure. 9 (a) show that normal current condition indicates current level in frequency domain has characteristic appears only in fundamental frequency. Whereas, the experimental test result in figure. 9 (b) that series AC arc fault indicates current level in frequency domain has characteristic appears at multiplies of fundamental frequency. The experimental test show that to identify series AC arc fault with current level appears at multiplies of fundamental frequency. figure. 9 (b) show that current level appears in frequency domain of $150 \mathrm{~Hz}, 250 \mathrm{~Hz}, 350 \mathrm{~Hz}, 450 \mathrm{~Hz}, 550 \mathrm{~Hz}$ and $650 \mathrm{~Hz}$. The experimental test of series AC arc fault characteristic is used as reference to protection.

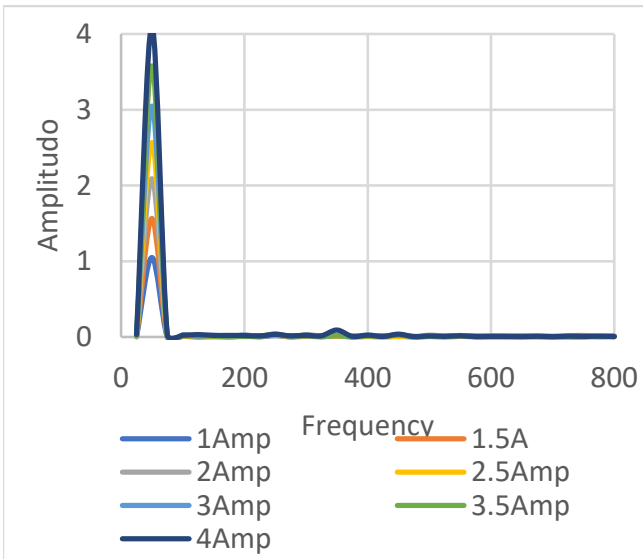

Figure. 9(a). Characteristic of normal current

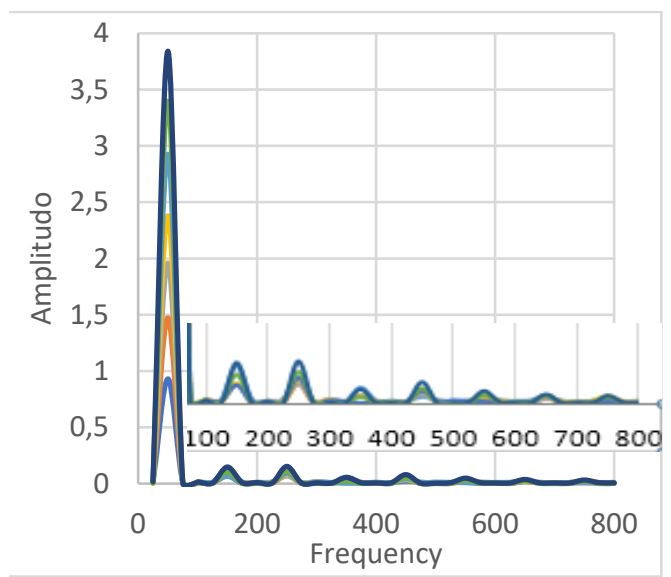

Figure. 9(b). Characteristic of series AC arc fault

\subsection{Experimental Test of Series AC Arc fault Protection System}

To evaluate the performance of series AC arc fault protection system, experimental test is performed. Experimental test of series AC arc fault protection system is focused on time to trip. Experimental test is varied by current level of $1 \mathrm{~A}$ until $4 \mathrm{~A}$ to analysis response of protection system in time to trip. Figures 10 (a)- (d) show the experiment result of protection system to operates isolate series AC arc fault with action to trip. In the figure. 10 (a) - (d) show that the current waveform in the normal condition has sinusoidal waveform when series AC arc fault occurs the current waveform changed by a shoulder at zero point. Protection system operates when series AC arc fault occurs. Table 2 shows that the protection system algorithm of series AC arc fault can work according to its function. The protection system speed of series $\mathrm{AC}$ arc fault has a time interval that varies between 0 to 1 second. The protection system speed depends on the amount of series AC arc fault value, the higher the value of series AC arc fault so the faster protection system isolates fault. 


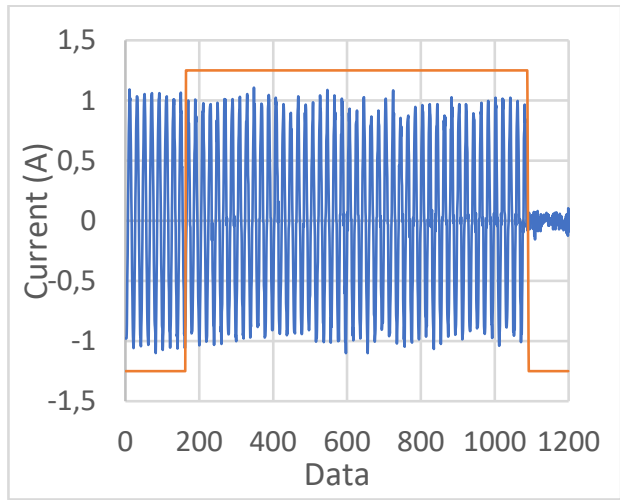

Figure. 10 (a). Time of arc fault breaker at $1 \mathrm{~A}$

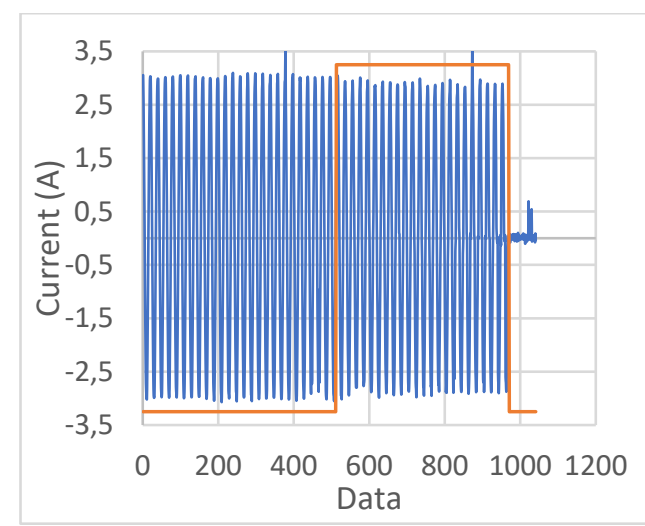

Figure. 10 (c). Time of arc fault breaker at $3 \mathrm{~A}$

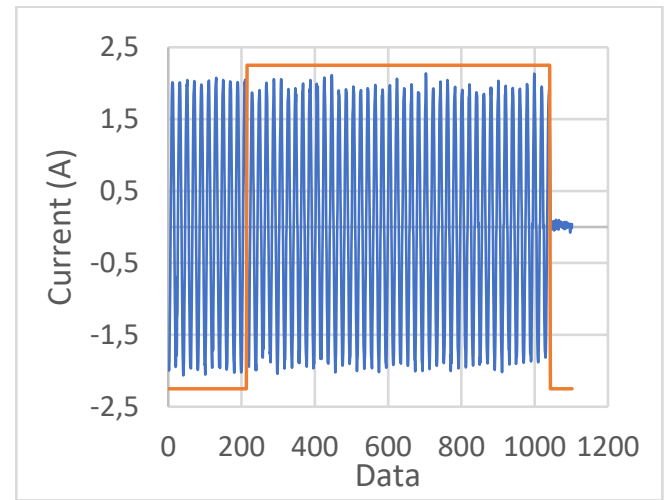

Figure. 10 (b). Time of arc fault breaker at $2 \mathrm{~A}$

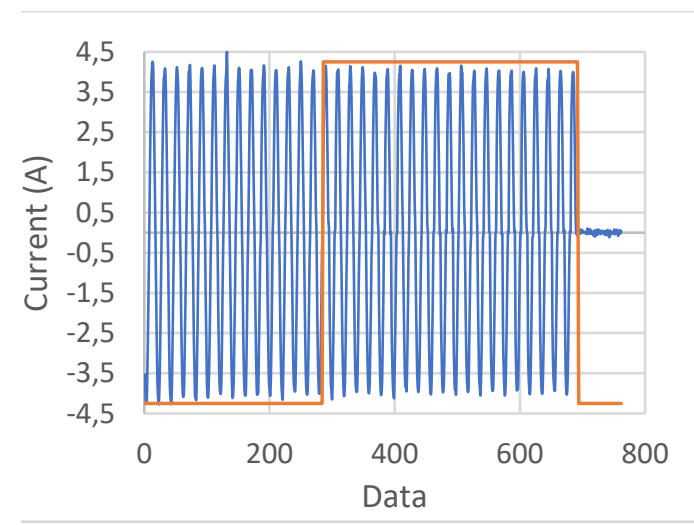

Figure. 10 (d). Time of arc fault breaker at $4 \mathrm{~A}$

Table 2. Experiment Result of Series AC Arc Fault Breaker

\begin{tabular}{|c|c|}
\hline $\begin{array}{c}\text { Current } \\
\text { Experimental }\end{array}$ & $\begin{array}{c}\text { Time Breaker } \\
\text { (s) }\end{array}$ \\
\hline $1 \mathrm{~A}$ & 0.98 \\
\hline $1.5 \mathrm{~A}$ & 0.6 \\
\hline $2 \mathrm{~A}$ & 0.76 \\
\hline $2.5 \mathrm{~A}$ & 0.56 \\
\hline $3 \mathrm{~A}$ & 0.3 \\
\hline $3.5 \mathrm{~A}$ & 0.6 \\
\hline $4 \mathrm{~A}$ & 0.43 \\
\hline
\end{tabular}

\section{CONCLUSION}

This paper proposes real time low voltage series AC arc fault breakers using microcontroller based on fast fourier transform, which microcontroller is used to compute FFT and as relay for breaker. Variations in the amount of are carried out to analyze the performance FFT. Moreover, FFT is tested in determine characteristics series AC arc fault with variations in the current 
level. As well as to perform system reliability, test the response time test for disturbance has been done with variations in current levels. The load is used to testing is a resistive load. The results show the proposed algorithm to detection and protection of series AC arc fault with STM32F7 microcontroller has good accuracy and fast operate.

\section{Acknowledgements}

This research is financially supported by Politeknik Elektronika Negeri Surabaya

\section{REFERENCES}

[1] N. Zamanan, J. K. Sykulski, and A. K. Al-Othman, Arcing high impedance fault detection using real coded genetic algorithm, the Third IASTED Asian Conference Power and Energy Systems, pp.35-39, 2007.

[2] D. C. Yu and S. H. Khan, An adaptive high and low impedance fault detection method, Power Delivery, IEEE Transactions on, vol. 9, pp.1812-1821, 1994.

[3] R. Patterson, W. Tyska, B. D. Russell, and B. M. Aucoin, A microprocessor-based digital feeder monitor with high-impedance fault detection, the 47th Annual Conference for Protective Relay Engineers- Texas A\&M University, 1994.

[4] G. Artale, A. Cataliotti, V. Cosentina, and G. Privitera, Experimental characterization of series arc faults in AC and DC electrical circuits, in Proc. Int. Conf. Instrum. Meas. Technol., Montevideo, Uruguay, May 2014, pp. 1015-1020.

[5] Syafi'i, M. H. R. A., Prasetyono, E., Khafidli, M. K., Anggriawan, D. O., \& Tjahjono, A. (2018, October). Real Time Series DC Arc Fault Detection Based on Fast Fourier Transform. In 2018 International Electronics Symposium on Engineering Technology and Applications (IES-ETA) (pp. 25-30). IEEE.

[6] Khafidli, M. K., Prasetyono, E., Anggriawan, D. O., Tjahjono, A., \& Syafii, M. H. R. A. (2018, October). Implementation AC Series Arc Fault Recognition using Mikrokontroller Based on Fast Fourier Transform. In 2018 International Electronics Symposium on Engineering Technology and Applications (IES-ETA) (pp. 31-36). IEEE.

[7] Z. Wang and R. S. Balog, Arc fault and flash signal analysis in DC distribution systems using waveformlet transformation, IEEE Trans. Smart Grid, vol. 6, no. 4, pp. 1955-1963, Jul. 2015

[8] C. Strobl, Arc fault detection in DC microgrids, in Proc. 1st Int. Conf. DC Microgrids, Atlanta, GA, USA, Jun. 2015, pp. 181-186

[9] S. C. Ji, Y. Liu, Y. Y. Zhu, and L. Y. Zhu, Study on the detection methods of DC series arc fault, High Voltage Eng., vol. 39, no. 9, pp. 2131-2137, 2013 
[10] G. Artale, A. Cataliotti, V. Cosentino, G. Privitera, Experimental characterization of series arc faults in AC and DC electrical circuits, Proceedings of the 2014 IEEE International Instrumentation and Measurement Technology Conference, I2MTC 2014, Montevideo, Uruguay, May 12-15, 2014, pp. 1015-1020.

[11] G. Artale, A. Cataliotti, V. Cosentino, G. Privitera, Arc fault detection equipment and method using low frequency harmonic current analysis, US Patent US 9,025,287, Assignee: STMicroelectronics. Grant Date: 05.05.2015

[12] Underwriter Laboratories Inc., UL standard for safety for arc-fault circuit interrupters, UL 1699, Second Edition, April 7, 2006

[13] Naidu M, Schoepf TJ, Gopalakrishnan S. Arc fault detection scheme for 42-V automotive DC networks using current shunt. IEEE Trans Power Electron 2006;21(3):633-9.

[14] Lin YH, Liu CW, Chen CS. A new PMU-based fault detection/location technique for transmission lines with consideration of arcing fault discrimination-Part I: Theory and algorithms. IEEE Trans Power Delivery 2004;19(4):1587-93.

[15] Engel JC. Combination AFCls: what they will and will not do. In: Proceedings of he 2012 IEEE IAS electrical safety workshop, Daytona Beach, FL, USA, January 2012. p. 1-18.

[16] Arc-fault circuit interrupters, UL Standard 1699-2008; 2008.

[17] $\mathrm{Su} \mathrm{WY,} \mathrm{Wu} \mathrm{CJ.} \mathrm{The} \mathrm{assessment} \mathrm{of} \mathrm{introduction} \mathrm{of} \mathrm{the} \mathrm{arc} \mathrm{fault} \mathrm{circuit}$ nterrupters. Report prepared for Institute of Occupational Safety and Health, Taipei, Taiwan, IOSH98-S302; 2010.

[18] Anatassopoulos, Vasilis.Basics on Digital Signal Processing (Transform-DFT-FFT) peresntation for Electronics Labolatory, Physisc Departement, University of Patras. 